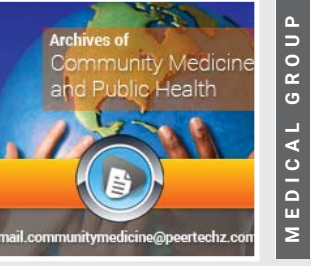

\title{
The future of elder care in Italy in COVID-19 pandemic times: Socio-economic considerations
}

Received: 21 October, 2020

Accepted: 28 October, 2020

Published: 29 October, 2020

*Corresponding author: Dr. Chiara Bugari, IRCCS INRCA, Centre for Socio-Economic Research on Ageing, Ancona, Italy, E-mail: chiara.bugari@yahoo.it

Keywords: Elder care; Private care assistants; Family caregivers; COVID-19

https://www.peertechz.com

Check for updates

\section{Chiara Bugari*and Giovanni Lamura}

IRCCS INRCA, Centre for Socio-Economic Research on Ageing, Ancona, Italy

\section{Abstract}

Target: Following the Covid-19 pandemic, the category of elderly people, in particular those who are not self-sufficient, is among those most affected in Italy. It is therefore urgent to identify innovative methods of support, in order to ensure a better quality of life in such a complex period from an epidemiological but also a socioeconomic point of view. At the center of these reflections is home care for the non self-sufficient elderly, analyzed through the role played by crucial actors such as private paid assistants and family caregivers, in order to understand how to best guarantee it in delicate circumstances.

Methods: Bibliographic research on the home situation of the elderly non self-sufficient population, through the comment of secondary statistical data updated on 1 July 2020 .

Results: From the limited data found, major problems are related first and foremost to the fear of and economic problems due to job losses of family members, who often contribute and support the assistance of the elderly from an economic point of view, with consequent difficulties in supporting dependent older relatives. The pandemic has accentuated and highlighted pre-existing socio-economic problems, but also made critical situations that were previously not too worrying.

Conclusion: The fear of social isolation due first to the pandemic and then to economic problems denotes an urgent need for public support, underlining at the same time the extreme importance of private home assistance. It is therefore necessary to invest in this sector, given the vastness of the elderly population in Italy, also through the preliminary collection of more targeted and updated data on the condition of frail older people and their families, in order to bring concrete and innovative solutions in the field elder care.

\section{Introduction}

If the frailty of the non self-sufficient elderly person requires general attention in "normal" life contexts, with the Covid-19 pandemic the pre-existing welfare problems have become accentuated and, at the moment, in a situation of probable second pandemic wave and exacerbation of the cases, these difficulties have become even more evident. The serious situation relating to infections in Assisted Health Residences (in Italian: RSA), with consequent lockdown and the difficulty in managing the elderly at home, has had and still has negative repercussions from a socio-economic point of view, sometimes already difficult in this range of age, both for those directly concerned and for their family members.

The non self-sufficient elderly person needs assistance and precise and continuous checks, often with economic difficulties in supporting them and often in situations of abandonment and loneliness [1]. The limitations in home care and nursing homes, a consequence of the attempts to stem the infection, have a devastating impact from a gerontological point of view [2].

Volunteers and associations are often called upon to support and combat too great a need, in some cases without sufficient skills, as well as care assistants hired privately by many families, often without regular contracts to guarantee them and the users concerned [3] . Considering the realistic possibility of new waves of viruses, it is therefore necessary to identify and implement ad hoc methodologies and interventions, to prevent, face and reduce often predictable damage. It is in fact necessary to be ready to be able to care for and support the elderly who are not selfsufficient in their environment, trying not to further burden the situation of past life, also intervening with help towards family caregivers, who cannot always cope, given the numerous problems working and consequently economic. 
As regards the Italian context, according to ISTAT, the COVID-19 pandemic has affected over 200,000 people and caused about 30,000 deaths [4]. Overall, there are about two million elderly people with disabilities living in the community, and over 300,000 in daytime and residential structures and rehabilitation centers, and they are the most affected category and at risk of contagion [5]. Isolation and "social" distancing have inevitably produced situations of notable socio-economic hardship. These people need help to be able to live the postpandemic in their usual environment, possibly limiting the changes and upheavals in an already complex daily life regardless of the tragedy of Covid-19,

\section{Recent industry research results}

To date it is necessary to take care of understanding and evaluating how especially isolated elderly lived during and after the lockdown. Among the recent studies conducted on the subject, the "Inclusive aging in place: IN-AGE" project addresses the issue of the frailty of elderly people and the related risks of social isolation, with the main objective of aging not in solitude ("aging in place, not aging alone "), often made even more complicated in conditions of poor health or even non self-sufficiency, situations of greater vulnerability and often difficulty or impossibility in asking for help (http:// www.lps.polimi.it/?page_id=2829). This project becomes even more important if defined in a historical moment such as the post-pandemic, where inevitably the situation becomes even more delicate.

Currently in Italy there is a large share of older people, including those who are not self-sufficient, who are living their older age both in nursing homes and at home. As regards the RSAs, the situation is easier to analyze, as professional staff are able to detect and transmit data, while the analysis of the impact of Covid-19 at home and in the community is more difficult. Within the IN-AGE project, it was very important to analyze the "hidden massacre", that is what happened and happens in the residences for the elderly, but it is also necessary to take care of what in the future of elderly people living at home, certainly a other part of the massacre even more hidden [6].

\section{Home care during and after the pandemic}

During and after the pandemic, and now again in the possible second wave phase we are experiencing, pre-existing balances between the elderly, family members and private assistants have inevitably broken. The lockdown often caused first precautionary home isolation, then social isolation out of fear or economic problems due to lower income from family members, so that, in some situations, about $30 \%$ of domestic workers were fired [7]. In other cases, it was the private care assistants who left, for fear of contagion, especially if without a work contract.

Even the position of the family caregiver, relative or similar who takes care of the elderly at home - a choice sometimes made precisely to better meet the expenses related to the family ménage, despite the numerous complications encountered in reconciling personal and professional life with the role of assistant - presented during the lockdown critical issues, due to movement difficulties, and the fact that not all these family members are suitable or trained to deal with welfare situations [8].

From this emerges a series of complications in the care of non self-sufficient elderly people, which indicates little attention and sensitivity, if not superficiality, towards such a fragile category on the part of politics and those who should protect them. Home care, in particular, should be monitored and regulated more with the occasion, strengthening therapeutic and assistance actions on site, recruiting qualified personnel, reviewing the costs borne by families in order to facilitate those belonging to the economically weaker groups.

\section{Residential structures and the pandemic}

In the nursing homes, the reality of elderly guests is characterized by complaints relating to the high costs of care and the lack of solutions that can guarantee a suitable distance, for often insufficient spaces, with respect to which it would be appropriate to incentivize residences with smaller dimensions and possibly agreements with the System National Healthcare [9].

A phenomenon that characterizes these structures is the strong demand for volunteers to support the assistance provided there, but to this end the trained health and sociohealth personnel should be increased, in order to better assist the non self-sufficient elderly thanks to a strengthening of nursing services, also in connection with the introduction of the family or community nurse.

The National Health System should aim at greater integration and coordination between territorial services and residential structures, as they are interdependent. This would contribute to making the nursing homes real places of care integrated into the reference context, with a view to being able to "make the last years of their existence live in the best possible way" even for those who have important functional limitations, thus overcoming the approach, unfortunately often prevalent today, of mere "caring" that characterizes the limited and essential activity of some structures [10]. Figure 1 shows the main critical issues identified in this regard in April 2020, which must absolutely be prevented and avoided in the evolution that hopefully can be started in the near future.

\section{Concluding remarks}

Launching ad hoc research and reform and development projects on a national scale to enhance the offer of equitable and territorially balanced services, would certainly have a positive impact on the quality of the care provided to the older population, both in pandemic and post-pandemic periods. The resulting improved ability to cope economically and socially with emergency situations would make it easier to overcome the difficulties posed by these events [11].

To this end, it would probably also be useful to activate regional operational centers which, by adopting a homogeneous emergency-urgency assessment system capable of ensuring immediate targeted interventions, thanks to telemedicine and adequate information systems, and thus allowing social and 


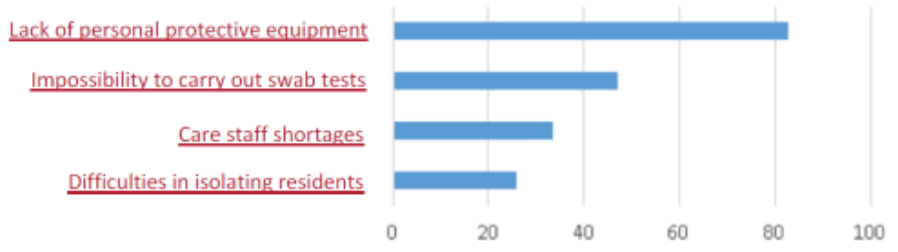

Figure 1: COVID-19 emergency: major problems detected in RSAs (\%).

health personnel to work in better conditions, and therefore with sure benefit for users, both from an epidemiological and an economic point of view [12].

The continuous and specialized training of dedicated staff and its strengthening would benefit the overall system of care provided, also through a shift of the center of gravity of the assistance system towards the home of frail elderly. Equally crucial will be the training of private care assistants, to be enhanced and not demonized, also through greater incentives of an economic nature, in the face of a mandatory professional qualification path [13].

Last, but not least, adequate support should be provided to family caregivers who are most committed to ensuring a dignified daily life for their non self-sufficient elderly. This would ideally take place by taking charge of them together with the care recipients, in order to guarantee caregivers the necessary support in terms of training, economic, carework balance, and anything else that can ensure that their commitment to the population frail elderly does not jeopardize their own well-being and state of health [14-16].

\section{References}

1. Armitage R, Nellums LB (2020) COVID-19 and the consequences of isolating the elderly. The Lancet, Public Health 5: 256. Link: https://bit.ly/2G8Yxqn
2. Camon F (2020) At eighty if you don't die they'll kill you. Apogeo 92.

3. Deluigi R (2017) Bonds of care. Caregivers, the elderly and families. Franco Angeli.

4. Serravalle E, Volpi R (2020) Coronavirus Covid-19. No! It didn't go well. The Green Lion: Turin.

5. ISS (2020) Survey nazionale sul contagio COVID nelle strutture residenziali sanitarie e sociosanitarie. Rome. Link: https://bit.ly/3jLJ4dH

6. Forni S, Nocci M, Bachini L, Gemmi F (2020) The response of the Tuscan hospital network to the Covid-19 pandemic: the August-September 2020 phase.

7. Galeotti S (2020) Coronavirus, the difficulties of home helps and carers: invisible and unaided. The regular fired $(+30 \%)$, the black ones kicked out. Most are hoping for emergency income - The stories. II Fatto Quotidiano.

8. Ganci A (2020) Elderly in post-Covid, complex management that will affect families “, Qds.it.

9. Vetrano D (2019) Continuity of care in Long-Term Care in Italy.

10. Veneto Region, ULSS 1, Assisting the non self-sufficient elderly in the post Covid-19 era: what future for the rsa?

11. Trabucchi M (2020) The elderly and Covid-19. From anguish to hope.

12. TAMBURINI F (2020) The books of the sun. A new economic model in the post-pandemic. The sun 24 hours.

13. Borella E, Faggian S (2019) Support those who support. Tools and guidance to support those caring for people with dementia. Franco Angeli.

14. Pietropaoli E (2020) COVID-19: the consequences of the isolation of the elderly and possible interventions. Portal of psychology and Psychiatry.

15. Cesari M, Proietti M (2020) COVID-19 in Italy: Ageism and Decision Making in a Pandemic. J Am Med Dir Assoc 21: 576-577. Link: https://bit.ly/2TyZATw

16. ISTAT (2020) The elderly: those most affected by the health emergency. Health and health in the face of the COVID-19 emergency. Annual report July 2020.
Discover a bigger Impact and Visibility of your article publication with

\section{Peertechz Publications}

Highlights

* Signatory publisher of ORCID

- Signatory Publisher of DORA (San Francisco Declaration on Research Assessment)

- Articles archived in worlds' renowned service providers such as Portico, CNKI, AGRIS, TDNet, Base (Bielefeld University Library), CrossRef, Scilit, J-Gate etc.

* Journals indexed in ICMJE, SHERPA/ROMEO, Google Scholar etc.

* OAI-PMH (Open Archives Initiative Protocol for Metadata Harvesting)

* Dedicated Editorial Board for every journal

- Accurate and rapid peer-review process

Increased citations of published articles through promotions

* Reduced timeline for article publication

Submit your articles and experience a new surge in publication services (https://www.peertechz.com/submission).

Peertechz journals wishes everlasting success in your every endeavours.

Copyright: @ 2020 Bugari C, et al. This is an open-access article distributed under the terms of the Creative Commons Attribution License, which permits unrestricted use, distribution, and reproduction in any medium, provided the original author and source are credited. 